DOI: $10.22559 /$ folklor.997

folklor/edebiyat, cilt:25, sayı:99, 2019/3

\title{
Çağdaş Tuva Yazılı Edebiyatının Gelişimi
}

\section{The Development of Contemporary Written Tuvan Literature}

\section{Zhazira Otyzbay*}

Öz

Çağdaş Tuva yazılı edebiyatının oluşmasına şifahi halk anlatıları başta olmak üzere folklor ürünleri öncülük etmiştir. İlk Tuva yazılı anıtlar Moğol yazı geleneği etkisiyle Eski Moğol dilinde yapılmıştır. Yeni dönem sürecinde doğan Tuva yazılı edebiyatı 1920'li yılların ikinci yarısında oluşturulmuş ve Tuva Halk Cumhuriyetinde yaşanan Sovyet rejiminin getirdiği kültürel ve sosyal devrim ile ilgilidir. 1930 yılından itibaren Tuva yazı dilinin oluşturulmasıyla Latin alfabesi esasında ilk Tuva dilindeki kitaplar yayınlanmıştır. 1930-1940 yılları arasındaki dönem yeni sosyalist Tuva edebi sanatın ilk oluşmaya başladığı dönem olarak kabul edilir. $\mathrm{Bu}$ dönemde yayımlanan edebi eserler ağırlıklı olarak Rus klasik edebiyatının önde gelen eserlerinin Tuva Türkçesine yapılan tercümeler ve Sovyet ideolojisi propagandasını içeren kitaplar olduğu görülmektedir. $\mathrm{Bu}$ dönemde Tuvaca yazılan eserler Çağdaş Tuva yazılı edebiyatının temelini oluşturmaktadır. Daha sonraki dönemlerde birçok Tuvalı yazar tarafından yerli halkın dünya görüşü, milli değerleri ve örf-âdet ve gelenekleri, inançları yanı sıra sosyal sorunları da ele alınan zengin eserler verilmiştir. Çalışmada Tuva yazılı edebiyatının oluşumunda önemli rol oynayan nesir, nazım yanı sıra Tuva çocuk edebiyatı ve dram alanında örnek teşkil eden ilk eserler ve yazarları hakkında bilgi verilmektedir.

Anahtar sözcükler: edebiyat, Tuva, Tuva edebiyatı, Tuva Türkçesi, Sibirya

Dr. öğr. üyesi. Pamukkale Ün. FEF Çağdaş Türk Lehçeleri ve Edebiyatları Bölümü jazirakentauly@gmail.com 


\begin{abstract}
Folk literature and folklore products have been pioneered by emergence of contemporary Tuvan literature. The first written Tuva monuments were made in the Mongolian language with the influence of Mongolian writing. The literature in the new period was created in the second half of the 1920s and is related to the cultural revolution of Tuva People's Republic. In 1930, the first Tuva language books were published in Latin alphabet. The period between 1930 and 1940 is considered to be the period when literary art first emerged in the new socialist Tuva. The literary works published in this period are mainly the books of the leading works of Russian classical literature including translations to Tuva language and the propaganda of Soviet ideology. The works written in this period form the basis of Contemporary Tuva literature. In later periods, many Tuvan writers have provided rich works on the Tuva native world view, national values and folk tradition, as well as the social problems. In this study is given information about first leading writers and their exemplary writings in the field of prose, poetry and also children literature and drama which are played important role in formation of contemporary Tuvan written literature.
\end{abstract}

Keywords: literature, Tuva, Tuvan literature, Tuvan Turkish, Siberia

\title{
Giriş
}

Güney Sibirya Türklerinden olan Tuva Türklerinin dili Türkiye'de SSCB'nin dağılmasından önce birkaç yükseköğretim kurumunda ve araştırma enstitüsünde öğretilmiş, 1992 yılından itibaren başta Ankara Üniversitesi ve Gazi Üniversitesi olmak üzere günümüze kadar birçok üniversitede açılmış olan Çağdaş Türk Lehçeleri ve Edebiyatları bölümlerinde Kuzey-doğu Türk lehçeleri anabilim dallarında öğretilmektedir. Türkiye'de Tuva Türkçesi üzerine yapılan araştırmalar nokta çalışmalar olup Tuva Türkçesi dilbilgisi, sözlük, atasözleri ve destanları üzerinde çalışmalar yapılmıştır. Bu çalışmaların arasında başta Prof. Dr. Mehmet Ölmez Tuva Türkçesinin dili, dilbilgisi ve atasözleri üzerinde yazıları yayınlanmıştır. Tuva Türkçesi ayrıntılı dilbilgisi, Tuva destanları, Tuva Türkçesi sözlüğü ve Tuva Türkçesindeki hikâye çevirileri Prof. Dr. Ekrem Arıkoğlu tarafından yayınlanmıştır. Tuva edebiyatının yazarları ve eserleri hakkında kısaca bilgi veren Prof. Dr. Ekrem Arıkoğlu'nun yazıları Türk Dünyası El Kitabı'nda yayınlanmıştır. Günümüzde Tuva Türkçesi üzerine yapılan çalışmalar gün geçtikçe çoğalmaktadır. Ancak Tuva edebiyatının gelişim süreci ve Tuva edebiyatının önde gelen yazarları ve eserleri hakkında ayrıntılı çalışmalar yapılmamıştır. Eldeki çalışma Tuva edebiyatı araştırmalarına katkıda bulunmak için Tuva yazılı edebiyatı türlerinin ve çocuk edebiyatının gelişim sürecini konu edinmektedir. Çalışmanın amacı Türkiye'de Tuva edebiyatı üzerinde çalışma yapmak isteyenlere veya Tuva edebiyatını merak eden okurlara çağdaş Tuva yazılı edebiyatının oluşum süreci hakkında bilgi vermek ve ilk ve önemli yazarlar ve eserleri ile tanıştırmaktır.

Çalışmada Tuva Türkçesinin yazı dili haline gelmeye başladığı 1917 devriminden itibaren oluşmaya başlayan yazılı Tuva edebiyatının 1990'lı yıllara kadarki önemli temsilcileri ve eserlerinden bahsedilmiştir. Çalışmanın bu yıllar ile sınırlanmış olması bu döneme kadar 
yapılan Tuva edebiyatının klasikleri haline gelen önemli edebi eserlerle Tuva edebiyatının gelişim sürecinin tamamlanmış olmasından kaynaklanmaktadır.

Tuva edebiyatı araştırmacısı N. Toburokov’a göre Tuva Türkçesi yazılı edebi dil olarak XVII. yüzyılda ülke topraklarına, halkın içine Budizm'in girmesi, 1758-1911 yılları arasında Çince, Mançuca ve Moğolcanın hakim olduğu Çin (Sin) İmparatorluğu boyunduruğu altında olduğu, daha sonra 1914 yılından itibaren Çarlık Rusya'nın himayesi altına girdiği ve en son 1921 yılında Tuva Halk Cumhuriyeti'nin kurulduğu dönemlerde SSCB'nin sosyalist dünya görüşü çerçevesinde gelişmiştir. Çarlık Rusya'nın boyunduruğu altına girmeden önce Tuva Türkleri ilk önce Moğol yazı dilini kullanarak çoğu zaman Moğolca eserler vermiştir, daha sonra Moğol yazısıyla Tuva Türkçesiyle eserler yazmıştır. Tuva Türkçesinin yazı dilinin oluşturulması ve Tuva edebiyatının milli Tuva Türkçesinde gelişiminin başlangıcı 1930 yılı olarak kabul edilir (Toburokov, 2016: 115).

\section{Tuva yazılı edebiyatının oluşumu}

Tuva yazılı edebiyatının oluşmasına şifahi halk anlatıları başta olmak üzere folklor ürünleri öncülük etmiştir. Bu anlatılar: kahramanlık anlatılar (maadırlıg tooldar), kahramanlık masallar (Tuva kahramanlık destanları), çeşitli konulardaki masallar (tooldar), efsaneler, mitler ve hikâyeler (toolçurgu çugaalar, töögülüg çugaalar), şarkısal şifahi ürünler, türküler, (ırı ve kojamıktar), örf-adet şiirleri (algış yöreelder), tekerlemeler (dürgen çugaalar) ve küçük parçalı folklor ürünleri, bilmeceler (tıvızıktar), atasözleri (üleger domaktar), belâgatli sözler (çeçen söster) şeklinde karşımıza çıkmaktadır. Bu ürünlerden Tuva atasözleri üzerinde Prof. Dr. Mehmet Ölmez "Tuva Atasözleri” adlı uzun makalesini yayınlamıştır. Bu makalesinde Tuva halk edebiyatı ve Tuva atasözleri hakkında ayrıntılı bilgi verilmektedir. Tuva kahramanlık destanları Prof. Dr. Ekrem Arıkoğlu tarafından Türkiye Türkçesine tercümesi yayınlanmıştır.

Tuva edebiyatının folklor kökenlerini dikkatle ve titizlikle inceleyen yazar ve araştırmacılar folklorun edebiyata etkisini buluyor ve edebiyatın bütün türlerinde bunu göstermektedirler. Tuva edebiyatı araştırmacılarından Toburokov'a göre diğer Türk lehçelerindeki milli edebiyat türlerinden farklı olarak Tuva edebiyatına Moğol folkloru aracılığıla Hint-TibetMoğol konuları, onların örf-adetleri ve fikirleri girmiştir. Bu şekilde Moğol dilli edebiyat ve folklor Tuva edebiyatına doğu edebiyatı unsurlarının girmesine aracılık etmiştir. Tuva Türkleri bu şekilde Moğol yazılı ürünlerinden "Geser” nüshaları ve Hint edebiyatının eserlerinden "Mahabharata", "Pançatantra" v.b. ile tanışmıştır. Bu, eserler Budizmin yaygınlaşmasına tesir etmiştir. Moğolca aracılığıyla giren Budist eserlerin etkisiyle Şamanizm ve Tengricilik, kısmen Maniheist inançlarına sahip olan Tuva Türkleri Budizm'e inanan halk haline gelmiştir. Bu, tüm halkın manevi gelişiminde ve Tuva Halk Cumhuriyeti'nin kurulmasında ilerici ve belirleyici rol oynamıştır (Toburokov, 2016:117).

Toburokov’un araştırmalarına göre ilk okur-yazar Tuva Türkleri Eski Moğol alfabesine hâkim olmuşlar ve bu alfabede sadece tarihçeler yazmakla kalmayıp, ayrı tarihi eserler de yazmışlardır. Tuva Beşeri ve Uygulamalı Sosyal-Ekonomik Araştırmalar Enstitüsü arşivinde 1200 elyazmanın bulunması tesadüf değildir. "Tuva Edebiyatının Tarihi” kitabının ilk cildinin yazarlarından G. O. Tudenov'un tespitlerinden sonra bu el yazmalar Tuva edebiyatının kaynakları olarak sayılmış, Tuva edebiyatı tarihinin derin altyapıya sahip olduğu anlaşıl- 
mıştır. Tuva Türkleri tarafından Eski Moğol yazı dilinde yazılan bu el yazmalarda dikkat edilecek noktalar çok. Orada Tuva hakkında sadece tarihi gerçekler yansıtılmakla kalmayıp, insanların portreleri, sanatsal düşüncenin özellikleri, hatta yazarların karakterleri oluşturulmuştur (Toburokov, 2016:118). G. O. Tudenov'un tespit ettiği ve Tuva edebiyatının kaynakları olarak saydığı bu Eski Moğol yazılarıyla yazılmış olan el yazmaları Tuva Türkçesinde mi Moğolca mı yazıldığı belirtilmemiştir.

Tuva nesrinin, nazmının, dramının folklor kökenlerini araştırırken "Tuva Edebiyatının Tarihi” kitabının ilk cildinin yazarları çok değerli bilgiler vermektedir. Tuva edebiyatı şiir dilinde halk ırları, kojamıktar belirli rol oynamışlardı. Bunların çoğu müzik eşliğinde icra edilirdi. Bu yüzden yerleşmiş sekizli kalıp ve kesin ritme sahiptiler. Bunların hepsi Tuva'nın ilk şairlerine üst düzey yazılı şiir metinlerini oluşturmada yardımcı oluyordu. Hem nesirde, hem nazımda efsaneler, anlatılar ve mitlerin özellikleri ve konuları kullanılmıştı. XIX. yüzyılın ikinci yarısında birçok folklor metni kaydedildiğinden, XX. yüzyılın başındaki yazarların öğreneceği çok kaynak vardı, ayrıca birçok yazar anne sütü ile halk eserlerini ruhlarına sindirmişlerdi. Oyunlar, piyesler Bolşevik devriminden önce milli, geleneksel unsurlar içerip, okur-yazar olmayan halka sözlü olarak yaygınlaştırılmış, devrimden sonra bu tür eserler Sovyet ideolojisinin yaygınlaştırılmasında birer propaganda amacıyla kullanılmıştır. Daha sonra bu ideoloji edebî yazılı eserler aracılığıyla yaygınlaştırılmaya başlamıştır. Tuva edebiyatındaki tüm Bolşevizm propagandası içeren oyunlar, piyesler başlangıçta Tuva yazarlar ekibi tarafından, daha sonra ayrı yazarlar tarafından yazılmıştır.

İlk Tuva yazılı anıtlar Moğol yazı geleneği etkisiyle Eski Moğol dilinde yapılmıştır. Yeni dönem sürecinde doğan edebiyat 1920'li yılların ikinci yarısında oluşturulmuş ve Tuva Halk Cumhuriyeti kültürel devrimi üzerine olmuştur. 1930 yılından itibaren Tuva yazı dilinin oluşturulmasıyla Latin alfabesi esasında ilk Tuva dilinde kitaplar yayınlanmıştır. Örneğin: 1931'de "Prangalar nasıl kırıldı" (Kinçini çaza şapkan); "Küçük inşaatçiler” (Biçii turguzukçular), 1934'de “Bizim emeğimiz” (Bistin aj11), 1936'da “Hadi Öğrenelim” (Öörenili) gibi okuma kitapları çıkmıştır.

1930-1940 yılları arasındaki dönem yeni sosyalist Tuva'da edebi sanatın ilk oluşmaya başladığı dönem olarak kabul edilir (Dongak, 2018: 29). Bu yıllarda Tuva Türkçesiyle sadece akraba halkların edebî eserleri ile kalmayıp, aynı zamanda Moğolca, Rusça eserlerden de tercümeler yapılmaya başlar. Bu süreç özellikle Tuva Halk Cumhuriyetinin kuruluşu yıllarında Tuva Sovyet edebiyatı tarihinde görüldügü gibi tüm edebî eserler devlet organlarının ideolojik kontrolü altında yayınlanmıştır. 1935 yılında Tuva Halk Cumhuriyeti’nin Küçük Meclis'in IV. Kurul toplantısı kararında Rus Sovyet edebiyatı ve Tuva aratlarının (bak. Notlar) eserlerinin Tuva Türkçesine tercümesinin yapılmasının önemine hususi olarak değinilmiştir. Ayrıca bu kararda edebiyatçılara destek olarak en iyi eser ödüllerinin verilmesi, edebiyat gecelerinin düzenlenmesi, eserlerin eleştiri seçimlerinin yapılması sağlanmış olduğu, Tuva Halk Cumhuriyeti Kültür Bakanlığına bağlı Tercüme bürolarının çalışmalarının güçlendirilmesinin öngörüldüğü 1964 yılı Tuva edebiyatının kısa tarihinde anlatılmaktadır. Bu eserlerin yazarları aynı zamanda 1937 yılında düzenlenen Puşkin günleri etkinliklerinin ilk büyük sanatsal tercüme yapma okulu haline geldiğini ve bunun ilk defa Rus nazmının Tuva Türkçesine tercüme edilmesi mümkün olmadığı yönündeki fikirlerin büyük bir yanılg1 
olduğunu gösteren ilk çalışmalar olduğunu yazmaktadırlar (Kalzan, 1964: 33-35). M. A. Hadahane kendisinin "Tuvinskaya proza” (Tuva Nesri) adlı monografisinde XX. yüzyılın başında Tuva'ya Rus öğretmenlerin ilk geldiği dönemden itibaren, 1908'de Turan şehrinde ilk defa okulun açılması ve 1931 'de Kızıl şehrinde ilk devlet kütüphanesinin açılması ile emekçi aratlara Rus klasik edebiyatı ve süreli yayınlarının tüm zenginliğinden faydalanma imkânının doğduğunu yazmaktadır (Hadahane, 1968: 10). Tuva nesrinin doğmasina 1937'deki A.S. Puşkin tercümeleri yanı sıra 1931'de Tuva Türkçesinde yazılan Lenin ve Bolşevik devrimi hakkındaki yayınların de etkisi olmuştur. Tuva yazarları ve edebî eser tercümanlarının bu tür yayınlar aracılığıyla edebiyat çalışmalarının doğasını derinden ve kesin olarak öğrenmişler, konu belirleme, olayların seçilmesi, karakterlerin resmedilmesi, süjelerin yapılması ve kahramanların oluşturulması için parlak araçların kullanılmasını öğrenmişlerdi (Hadahane, 1968: 10-11). İlk Rus dilinden Tuva Türkçesine yapılan tercümelerden olan 1931'de 5000 adet basılan on sekiz sayfalık "Paşkı Lenin" (Öğretmen Lenin) adlı kitapta "Lenin'in tarihini Rusça kitaptan tercüme eden Şırgay-ool ve Buzıkayev’tir” diye belirtilmişstir. "Lenin bolgaş biçii ulustarnın dugayı" (Lenin ve küçük milletler hakkında) adlı metni Tuva Türkü S. Toka yazmıştır. D. S. Kuular, Rus edebiyatının Tuva edebiyatına etkisini, yazarlar arasındaki temasları ve tercüme çalışmaları hakkında anlatırken A. A. Palmbah'ın sivil toplum faaliyetlerindeki etkisi ve onun Tuva Türkçesinde yazılan eserleri ve Rusçaya tercüme ettiği çalışmalarından da bahseder. Tuva Türklerinin edebiyat ve sanat dünyasının başka milletlerin dünyası ile etkileşimi aynı zamanda o dönemlerde popüler olan halk devrimi şarkıları ve şiirlerinin Moğolcadan ve Rusçadan tercüme edilmesi ile olmuştur (Kuular, 1970: 11-14).

Tuva edebiyatının doğduğu dönemde, tercüme çalışmaları Tuva yazarlarının profesyonel gelişmesine ve en önemlisi de Tuva edebiyatı eleştirisinin gelişmesine de büyük katkıda bulunmuş olduğu 1975 yılındaki Tuva edebiyatı tarihsel denemelerde belirtilmiştir. İlk defa tercüme edilen eserler "Biçii turguzukçular" (Küçük inşaatçiler) ve "Pistin ajıll" (Bizim emeğimiz) adlı okuma kitapları idi (Dongak, 2018: 30). Bu kitapların yazarları ana dilinde halkın kolay anlayacağı şekilde devrim dünyasının en önemli olaylarını ve okul hayatının günlerini anlatmışlardı. Tuva edebî hayatının o dönemdeki parlak eserlerinden biri olan A. S. Puşkin'in "Ya pamyatnik vozdvig sebe nerukotvornıy" (Ben kendime elle yapılmayan anıt diktim” adlı Rusça şiirini S. Pürbü "Turaskaal (Anıt) olarak tercüme etmiştir. Bunun yanı sıra ilk tercüme edilen eserler arasında M. İdam Sürün'ün tercüme ettiği Lebedev-Kumaç'ın “İnternatsional” (Enternasyonel) şarkısı, birkaç kişinin ekip olarak tercüme ettiği A. S. Puşkin'in “Yüzbaşının Kızı”, S. Sarıg-ool’un tercüme ettiği M. A. Gorki’nin “Makar Çudra” hikâyeleri de var. A. K. Kalzan Tuva Türkçesine yapılan bu tercümelerin Tuva edebî dilinin oluşumu ve gelişmesi için itici güç olduğunu yazmıştır (TLTO: 52-53).

Tuva edebiyatının kurucuları V. Kok-ool, S. Sarıg-ool, S. Pürbü, Salçak Toka, O. Saganool, B. Hovenmey gibi yazarlar sayılır. Onların cumhuriyetin gazete ve dergileri sayfalarında yayımlanmış olan piyesleri, şiirleri, hikâyeleri, daha sonraki dönemde uzun hikâyeler (povest) ve romanları Tuva'da edebiyat sanatı olgusunu sağlamlaştırmış ve çağdaş Tuva yazılı edebiyatının temelini kurmuştur. 1946 yılından itibaren "Ulug-Hem” (Yenisey) adlı edebîsanatsal almanak yayımlanmaya başlamıştır. 


\section{Tuva edebiyatında nesir}

Tuva nesri hikâye (çeçen çugaa), deneme, uzun hikâyeler (povestler, tooju) ve roman türlerinden oluşmaktadır. 1930 yıllarındaki erken döneme ait küçük nesir eserler kurgusal hatıralar, okuma hikâyeleri anonim tefrika şeklinde yazılmıştır. 1930-60'lı yıllarda daha büyük biçimdeki eserlerin ortaya çıkmasıyla hikâyelerin, uzun hikâyelerin ve romanların türleri belirlenmiştir. 1950'li yılların ikinci yarısında ve 1960'lı yılların başlarında S. Toka'nın, S. Sarı-ool'un, O. Sagan-ool'un, S. Sürün-ool'un, S. Pürbü'nün kitapları çıkmıştır. 1951'de O. Sagan-ool'un “Sumudan kelgen ool” (Sumudan gelen oğlan), 1959'da S. Pürbü’nün “Ergeppee Dugayında Tooju” (Ergeppee Hakkında Uzun Hikâye), avcıların hayatındaki olaylar hakkında 1958'de S. Pürbü’nün “Şınappaynın çugaazı” (Şınappay’ın Hikâyeleri), 1969'da “Kiji boydustun tölü” (İnsan Doğanın Çocuğu), kahramanların özel hayatlarındaki olaylar hakkında S. Sarıg-ool'un "Çogaaldar çınndızı" (Hikâyeler toplaması), 1 S. Sürün-ool'un (Hikâyeler) gibi Tuva'nın geçmişi ve bugünü ile ilgili konuları kapsayan çeşitli eserler yayımlanmıştır. 1960'lı yıllarda M. Kenin-Lopsan'ın, O. Sagan-ool’un, K.E. Kudaji’nin, S. Sarıg-ool'un romanları çıkmaya başlamıştır. Tuva edebiyatında XX. yüzyılın son on yılında ve XXI. yy. başlarında en çok tanınan nesir eserler S. Toka'nın “Arattın sözü” (Arat’ın Sözü), M. Kenin-Lopsan’ın “Çılgıçının öö” (Çoban’ın Otağı) (1980), "Buyan Badırgı” (Buyan Badırg1) (1999), "Çitken urug” (Kaybolan Kız) (2001) romanları çıkmıştır. S. Sarı-ool’un ünlü "Angır-oolduy toojuzu" (Angır-ool'un hikâyesi) adlı dilogu Rusçaya çevrilmiştir. Dört oyunluk bölüm halinde K. E. Kudaji’nin “Uygu çok Ulug-Hem” (Uykusuz Yenisey) (1973-1990), O. Sagan-ool'un çağdaşları hakkındaki romanları "Döspester" (Dayanmayanlar), Töreen kijiler (Akrabalar), S. Sürün-ool'un uzun hikâye ve romanları toplumsal psikolojik manevi problemleri aydınlatmaya çalışır. "Avazınga dạgırak" (Annenin Yemini), "Tıvalaar Kuskun” (Tuvaca Konuşan Kuzgun), M. Duyungar'ın nesir eseri “Börü dünü” (Kurtlu Gece) (1991), tarihî konuları içeren E. Dongak’ın “Sıın çadı” (Maralın Büyüsü) (1986), O. Seglenmey’in (Hayat İçin Mücadele), M. Kojeldey’in “Töreen çurttan 1rakka” (Vatandan Uzakta) gibi uzun hikâye ve romanlar ele alınmıştır. Tuva nesrinin renkli tablosunu V. Monguş'un "Katkı bajı katkan eves" (Hem kahkaha ve hem günah) (1975) hiciv hikâyeleri ve N. Dorju'nun şiirsel kısa hikâyeleri "Sırgalar" (Küpeler) (1989) tamamlar.

Tarihî konuları ele alan B. B Taraaçı’nın “Kaygal” (Kaygal) (1994) adlı hikâyesi ve B. İrgit' in “Arzılan Küderek" (Arslan Küderek) (1996) adlı tarihî romanı önemli edebî olay haline gelen eserlerdir. K. E. Kudaji’nin Rusça "Plaç” (Ağlayış) (1999) adlı belgesel tarzındaki uzun detektif hikâyesinde ve Ş. Monguş'un hikâyelerinde manevi kriz ve onun sosyal sonuçları, aile değerlerinin ve milli geleneklerin düşüşü ile ilgili konular ele alınmıştır.

\section{Tuva edebiyatında nazım}

Sözlü yaratıcılığın en popüler türü olarak şiir tematik ve tür çeşitliliği ile ayırt edilir. Tuva Türkçesinde ilk yazılı şiirler A. S. Puşkin'in şiirlerinin ve Bolşevik ihtilali ile ilgili propaganda içerikli Rusça şiirlerin Tuva Türkçesine tercüme edilmesi ile başlar. Daha sonraki dönemlerde çocuklar için okuma ve ders kitaplarında Rusça çocuk şiirlerden esinlenerek Tuva Türkçesinde şiirler yazılmaya başlamıştır. Daha sonraki dönemlerde Tuva Türkçesinde söz ustası olan şairler yetişmiştir. S. Saryg-ool, B. Hövenmey gibi birçok ilk nitelikli şairlerin ve 
daha geç dönemdeki Sovyet Tuva şairlerinin şiirleri sosyalist toplumsal inşaat konularını ele alır. Ü. Küzengeş'in şiirlerinde ise vatandaşlık motifler işlenmektedir. S. Pürbü, M. Dorju, V. Seren-ool, A. Darjay, Z. Namzıray’ın şiirleri aşk konuları üzerine yazılmıştır. 1990'larda şiirin sanatsal özelliğinde değişim meydana gelir. Tuva geleneksel halk şiirinin kalıplaşmış sekizli ve on ikili kalıp biçimi terkedilmeye, biçimsel yapı genişlemeye ve yeni ritmik temel tercih edilmeye başlar. Örneğin, K. Çerlig-ool ve M. Kujuget'in şiirlerinde nadir rastlanan dokuzlu kalıp kullanılır. E. Mijit ise ilk defa serbest ölçü olan nesir biçimindeki şiirler yazmaya başlar.

\section{Tuva çocuk edebiyatı}

Tuva yazılı çocuk edebiyatının ilk kitapları çeviri kitaplardan esinlenerek yazılmış kitaplar olarak karşımıza çıkar. Sovyetler Birliği’ndeki bütün halkların Sovyet çocuk edebiyatı gibi Tuva çocuk edebiyatı önemli siyasi araç olarak ideolojik amaçlara ve yeni sanat kurallarına tabi tutuluyordu. Örneğin, 1932, 1933, 1934 yıllarındaki "Biçii turguzukçular" (Küçük inşaatçiler) kitabı ağırlıklı olarak orta öğretim öğrenciler hakkındaki hikâyeleri içerir. Bu hikâyeler Sovyet ders kitapları modeline göre hazırlanmıştır. Bu kitapta, kitabın tercüme olduğu belirtilmese de, ilk sayfadaki açıklamada Sovyet keşif gezileri bilimsel birliğinin o yıllarda birkaç yayının hazırlanmasında işbirliği yaptığı belirtilmiştir. Bu kitaba alınan hikâyelerin içeriğine göre gerçekten de hazırlayanların Rus dilinde yazılan kitaplara dayanarak hazırladığı, öğretim materyallerinin çoğu alıntı olduğu ve Tuva Türklerinin gerçek hayatına uyarlanmaya çalışıldığı açıkça görülmektedir. Örneğin: "Kadarçı Biçe” (Çoban Biçe) ve "Hemege" (Gemide) şiirlerinin metninin kafiye düzeni geleneksel Tuva kafiye yapısı ile ilgisi olmayıp, Rus şiirinin kafiye özelliklerini barındırması, metinlerin alıntılandığı dildeki özelliklerle beraber yazıldığını göstermektedir (Dongak, 2018: 30).

“Uruglar Nomu” (Çocuklar İçin Kitap) adlı kitap, N. Oleynikov’un “Kartina” (Tablo) adlı hikâyesinin Sergey Pürbü tarafından "Çuruk” (Resim) adıyla Tuva Türkçesine yapılan tercümesini ve V. Valde'nin (Pavlik Semyonov adındaki karakol) adlı hikâyesinin Lagbujap tarafından "Pavlik Semenovtun Adı-Bile Adaan Kızıgaar Taynılı Turar Çer" adı ile Tuva Türkçesine yapılan tercümesini içerir. Her iki hikâye de "şerig kiji çugaazı" (asker hikâyesi) ve "şkolaçı urug çugaazı" (öğrenci hikâyesi) şeklinde belirtilmiştir. Bu edebî tür tanımlarında Tuva nesrindeki edebiyat bilimi anlayışında "çeçen çugaa" (kısa hikâyeler) diye adlandırilan yeni bir türün doğmasına sebep olmuştur (Dongak, 2018: 30-31).

Tuva çocuk edebiyatının temsilcileri L. Çadamba, S. Sarıg-ool, Eker-ool, Keçil-ool olarak karşımıza çıkar. Ayrıca kendi hikâyeleri ile O. Biçe-ool, H. Oydan-ool, M. Ölçey-ool "Rasskazıy deduşki Hooreera" (Dede Hööreer'in hikâyeleri) eseri ile, anlatıları ile S. Taspay, bilmeceli hikâyeleri ile A. Şoyun, Rusça yazdığg "Tayna tsvetuşey ivı” (Çiçek Açan Söğüdün Sırrı) adlı uzun hikâyesi ile E. Tanova da Tuva çocuk edebiyatının önde gelen isimlerindendir.

\section{Tuva edebiyatında dram}

1930’lu yıllarda ilk Tuva dram eserler ortaya çıkmaya başlamıştır. Örneğin: "Ham-ool”, "Han Yasası”, “Çeçen-kıs” gibi toplu yazarların eserleri, ayrıca A. Palmbah'ın 1934'teki 
“Kolhozka saat kılırlarnı uzutkaalııar”, (Kolhoz Karşıtlarını Etkisiz Hale Getirelim) Salçak Toka'nın 1935'teki (Kadın), V. Kok-ool'un 1935'teki (Cut'u Unutmayı) gibi propaganda içerikli piyesler yayınlanmıştır. 1936 yılında kurulmuş olan Öğrenim Birliği bünyesindeki tiyatro stüdyosunun Tuva'da dramın gelişmesine büyük etkisi olmuştur.

Tuva Türkçesinde yazılan dram eserlerini S. Toka’nın “Tongur-ool” ve K. Kudaji’nin “Dolumanın huulgazını” (Doluma’nınYaramazlıkları) adlı klasikleşmiş komedileri, "V. Kökool’un "Hayıran Bot” adlı trajedisi, S. Pürbü’nün (Kızıl Akım), O. Sagan-ool’un (Uyanış) adlı piyesleri temsil eder. Bunun yanı sıra çağdaş piyeslerin yazarları olan V. Seren-ool, E. Tanova, K. Sagdı, O. Çılgı̨̧ı, E. Mijit de Tuva dramının önde gelen isimleridir. Ayrıca izlenim başarısını elde eden O. Çılgıçı’nın “Kombikorm, şlyapa i lyubov” (Yem, şapka ve aşk) (1987), “Krovavıye sledı" (Kanlı İzler) (1991), E. Mijit’in "Kto tıy Sübedey Batır?” (Kimsin sen Sübedey Bahadır?), "Vihr Kara-daga” (Kara-Dağ’ın zirvesi) adlı Rusça piyesleri de değer bulmuştur. E. Tanova'nın "Volşebnaya strela" (Sihirli Yay) adlı çocuk piyesi başarıyı yakalamıştır.

\section{Tuva cumhuriyeti dışındaki Tuva edebiyatı}

Tuva Cumhuriyeti sınırları dışında Tuvaca ve Rusça olmak üzere iki dilli şair E. Mijit'in eserleri ün kazanmıştır. Onun Rusça yazdığı “Ojivşeye Vremya” (Dirilen Zaman), “Sem' svetil'nikov” (Yedi Kandil) v.s. eserleri sanatsal özgünlük, şiir kahramanının şahsi dünyasına derinden girmesi, ciddi felsefi meseleleri anlamlandırmasi ile farklılık göstermiştir. E. Mijit' in serbest şiirleri "Yunost”(Gençlik), “Zemlya Sibir” (Sibirya Toprağı), "Literaturnaya Üçyoba” (Edebiyat Öğrenimi), "Ulug Hem” (Yenisey nehri) gibi dergilerde yayımlanmıştır. Tuva'nın Rus dilli edebiyatı M. Pahomov'un tarihsel uzun hikâyeleri ile, S. Kozlova'nın şiirsel hikâyeleri ve destanları ile, A. Emelyanov’un, E. Antufyeva'nın şarkı sözleri, V. Buzıkayeva’nın v.d. nesirleri ile temsil edilir ve bu eserler Tuva'nın çağdaş edebiyatın gelişim sürecinin bir parçası olarak görülür.

1980’lerin ikinci yarısından bu yana “Ulug-Hem” (Yenisey nehri) ve "Şın” (Gerçek) gazetesinin sayfalarında Moğolistanlı Tuva yazarlarının şiirleri yayımlanmaktadır. Moğolistan'ın Bayan Ölgiy bölgesi Sengel beldesinde doğup, yetişen Tuva Türklerinden olan Leipzig Üniversitesi mezunu Avrupa'da ün kazanmış Ç. Galsan (İrgit Çınak oglu Kalzan) Alman ve Moğol dillerinde birçok eser yazarak Altay Tuvalarının hayatını, tarihini, kültürünü ve şifahi halk eserlerini tanıtması ile değer görmüştür.

\section{Sonuç}

Tuva Türklerinin milli yazı dili ve yazılı edebiyatının oluşma ve gelişme döneminin başlangıcı olarak sayılan 1930-1940 yıllarında Tuva Türklerinin milli yazı dili oluşmadan önce çok zengin şifahi halk edebiyatı, folklor ürünlerinin yazıya dökülmesi yanı sıra Rusçadan aktarılan tercüme eserler etkin bir şekilde öncelikle çocuk edebiyatı olmak üzere genel Tuva edebiyatının oluşturulmasında ve geliştirilmesinde önemli araç olmuştur. Bu eserler o dönemin Bolşevik ve Sovyet siyasal ideolojik edebiyatı ile doğrudan ilgili olduğu açıkça görülmektedir. Tercüme edebiyatı Tuva Türkçesinin bir ana dil olarak yeni düzende sözvarlığının, 
terminolojinin zenginleşmesinde, Tuva Türkü şairlerinin şiir tekniğinde kalıp genişlemesinde ve Tuva edebî dilinin oluşmasına ve gelişmesine sınırsız imkanlar vermiştir. Öte yandan yazılı edebiyatın Bolşevik- Sovyet siyasal ideolojisi kontrolünde oluşturulması ve geliştirilmesi okuyucuların zihniyeti ve dünya görüşünün bu siyasal ideoloji çerçevesinde gelişmesi için bir propaganda aracı olarak kullanıldığını açıktır. Siyasal sansüre rağmen Tuva edebiyatında Tuva Türklerinin milli değerleri ve yerel dünya görüşünü içeren ve sosyal sorunların ele alındığı zengin edebî eserler Tuva Türklerinin parlak edebiyat temsilcileri tarafından ortaya konulmuştur.

\section{Notlar:}

Makalenin 4. sayfasında geçen “arat” sözcüğü Tuva Türkçesinde Bolşevik devriminden sonra Bolşevik taraftarı Tuvalı emekçi işçi kesime mensup insanlara söylenen sözdür.

\section{Kaynaklar}

Aça, M. (2011). Tuva atasözleri. Karadeniz, Y11 3, Say1 2.

Arıkoğlu E. (1998). Tuva edebiyatı. Türk dünyası el kitabı. Türk Kültürünü Araştırma Enstitüsü.

Arıkoğlu E. (2003). Tuva Türkçesi sözlüğü. Klara Kuular. Türk Dili Kurumu.

Arıkoğlu E. (2007). Tuva destanları. Buyan Borbaanay. Türk Dil Kurumu.

Bad1-Monge, E. T. (2004). Natsionalnoye svoyeobraziye hudojesstvennoy detali v tuvinskoy proze. Abakan: Tema dissertatsii i avtoreferata po VAK 10.01.02.

Evlahova İ. (1970). Pisateli Tuvı. Kızıl: Bibliyografiçeski spravoçnik.

Hadahane M.A. (1965). Tuvinskiye rasskazı. Sibirskye ogni, N 11.

Hadahane M. A., (1968). Tuvinskaya proza. Kız1l: Tuvinskoye knijnoye izdatel'stvo.

Hadahane M.A. (1986). Literaturnaya Tuva. Kızıl: Tuvinskoye knijnoye izdatel'stvo.

Kalzan A. K. Ed. (1964). Tıva literatura: dopçu töögüzü. Kızıl: Tıvanı̀ nom ündürer çeri.

Kalzan A. K. (1980). Klassiktig Orus literaturanı tıva dılçe oçuldurup turarı. Amıdıral bolgaş literatura: tıva çogaal dugayında bodaldar, s. 79-10, Kızıl: Tuvinskoye knijnoye izdatel'stvo.

Kara-Ool E., Oorjak S. (1982). Pisateli tuvı. Kızıl: Tıvanın nom ündürer çeri.

Kombu S. S. (2012). Puti razvitiya tuvinskoy literaturı. Tuvinskaya literatura: slovar, Ed. Monguş D. A., Trifonova M. L., Novosibirsk.

KİTSL: (Yazar adı belirtilmemiştir) (1975). Kratkaya istoriya tuvinskoy sovetskoy literaturı. Kızıl.

Kuular D. S. (1970). Tuvinskaya poeziya oçerk istorii. Kızıl: Tuvinskoye Knijnoye izdatel'stvo.

Ölmez M. (), Tuva atasözlerinden seçmeler, Sibirya incelemeleri, Göttingen - İstanbul. — 4.1, 2009: 51-128.

Ölmez M. (1996).Tuvalar ve Tuvaca. Çağdaş Türk Dili, Sayı 95.

Tenişev, E. R. ed.(1968). Tuvisko-russkiy slovar'. Moskova: Soveskaya entsiklopediya.

TLTO: (Yazar adı belirtilmemiştir) (1975). Tıva literaturanın töögüzünün oçerkteri. Kızıl: Tıvanı̀ nom ündürer çeri. 


\section{İnternet kaynakları}

Dongak, U. A. (2018). Osobennosti Pervıh Perevodnıh Proizvedenii Tuvinskoy Literaturı Tambov: Gramota. Erişim adresi: www.gramota.net/materials/2/2018/7-1/6.html (10.12.2018).

Dongak U. A. (2009). Tuvinskaya Literatura, İstorçeskaya Entsiklopediya Sibiri, Erişim adresi:http:// irkipedia.ru/content/tuvinskaya_literatura_istoricheskaya_enciklopediya_sibiri_2009. (10.12.2018).

Toburokov N. N. (2016), Peresmotr istorii tuvinskoy literaturı, Novıye İssledovaniya Tuvı, Erişim adresi: http://nit.tuva.asia/nit/article/view/79 (12.12.2018). 